\title{
Fortalecimiento de los pueblos indígenas del Ecuador
}

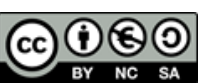

\section{Strengthening of indigenous peoples of Ecuador}

\author{
Pablo Homero Velasteguí López. ${ }^{1}$
}

Resumen.

DOI: $\underline{\text { https://doi.org/10.33262/concienciadigital.v1i1.939 }}$

Ecuador es una nación multiétnica y pluricultural. Su población sobrepasa los 14 millones de habitantes. De ella, más de 5 millones y medio viven en la Cordillera de los Andes Sierra. En la Costa del Pacífico la cifra se acerca a los 6 millones y medio. En la Selva Amazónica Amazonía hay más de 600 mil habitantes, y en Islas Galápagos cerca de 17 mil.

En sus tres regiones continentales conviven 14 nacionalidades indígenas con tradiciones diversas y su propia cosmovisión. Las nacionalidades indígenas amazónicas más conocidas son: Huairona, Achurar, Shuar, Cofán, Siona-Secoya, Shiwiar y Zápalo. Los tajeara, parientes de los huaorani, conforman otro pueblo de la zona pero éste fue declarado como "intangible" por el Estado, en respeto a su voluntad de vivir alejados de la civilización.

En la sierra, en los Cordillera de los Andes y en el austro, están los quichuas de la sierra con pueblos como los Otavalo, salasacas, cañarís y sargueros. En la parte norte se encuentra la comunidad de los awa. En la costa del Pacífico están los cachis, táchalas y huanca vilcas. En las ciudades y pueblos viven mestizos, blancos y afro ecuatorianos, aunque también se dan importantes migraciones del campo a la ciudad.

En el ecuador hay diferentes pueblos indígenas que podemos conocerlo a fondo sus raíces y sus costumbres. Ya que su idioma es muy elemental para nosotros y saber o aprender de ellos su lengua kichwa y así conocerlos más.

Palabras claves: Pueblos y nacionalidades del ecuador

\footnotetext{
${ }^{1}$ Ciencia digital, Ambato, Ecuador, luisefrainvelastegui@cienciadigital.org
} 


\section{Abstract.}

Ecuador is a multiethnic and pluricultural nation. Its population exceeds 14 million inhabitants. From it, more than 5 million and a half live in the Andes Mountains. In the Pacific Coast the figure is close to 6 million and a half. In the Amazon Amazon Forest there are more than 600 thousand inhabitants, and in the Galapagos Islands about 17 thousand.

In its three continental regions, 14 indigenous nationalities coexist with diverse traditions and their own worldview. The best-known Amazonian nationalities are: Huairona, Achurar, Shuar, Cofán, Siona-Secoya, Shiwiar and Zápalo. The Tajeara, relatives of the Huaorani, make up another town in the area but it was declared as "intangible" by the State, in respect to their willingness to live away from civilization. In the mountains, in the Cordillera de los Andes and in the austro, there are the Quichuas of the mountains with towns such as the Otavalos, Salaacas, Cañarís and Sargueros. In the northern part is the community of the awa. On the Pacific coast are the cachis, táchalas and huanca vilcas. Mestizos, whites and Afro-Ecuadorians live in cities and towns, although there are also important migrations from the countryside to the city.

In Ecuador there are different indigenous peoples that we can know in depth their roots and customs. Since their language is very elementary for us and know or learn from them their Kichwa language and thus know them more.

Keywords: Peoples and nationalities of Ecuador

\section{Introducción.}

Explicar lo que denominamos conciencia étnica es difícil para quien, sintiéndose parte de su propio grupo, no ha tenido que identificarse con dos colectividades. Solamente con el ánimo de ilustrar, los ecuatorianos, en donde quiera que nos encontremos viviendo, disfrutamos los éxitos del país, el orgullo nos invade, nos sentimos más ecuatorianos cuando triunfamos como nación, y lo mismo le ocurre a cualquier persona perteneciente a una etnia propia porque también se sabe ecuatoriano, pero a la vez, y de igual manera, disfrutan y se llenan de orgullo con los éxitos de su grupo porque los enlaza una identidad con éste, viven y piensan en función de su colectividad y del país, y eso es parte de lo unitario en relación con su propia conciencia étnica.

Por otro lado, un acercamiento a lo pluricultural necesariamente nos lleva a plantearnos lo que es una cosmovisión. Cada persona tiene un enfoque de lo que le rodea, de las cosas, de la vida, de la justicia, del mundo etc., esta visión propia del cosmos trae siempre una carga cultural, las manifestaciones sociales, políticas, económicas, filosóficas de su colectivo. La 
existencia de diversas etnias conlleva diversas cosmovisiones, es decir, varias culturas con orientaciones propias, diferentes unas de otras, lo cual enriquece una sociedad pues despierta nuevas formas de desarrollo. El Estado tiene la exigente labor de garantizar que la cosmovisión de las otras culturas, conocimientos, sabidurías, puedan compenetrarse pacíficamente en términos interculturales y de fortalecimiento de la identidad nacional.

El Art. 1 de la Constitución Política del Estado reconoce, como forma de la unidad nacional, el principio de respeto a la diversidad étnica y cultural y, en consecuencia, el trato igualitario para las diferentes culturas. Diversas manifestaciones de lo unitario presenta la normativa de la carta fundamental, por ejemplo al señalar que "La soberanía radica en el pueblo", o en su relación con la diversidad cuando indica "El Estado respeta o estimula el desarrollo de todas las lenguas de los ecuatorianos. El castellano es el idioma oficial. El quichua, el shuar y los demás idiomas ancestrales son de uso oficial para los pueblos indígenas" o al manifestar que son deberes primordiales del Estado "Fortalecer la unidad nacional en la diversidad". Una sociedad que reconoce la diversidad no debe privilegiar prácticas de una determinada cosmovisión, ni pretender que un grupo humano desista de sus tradiciones, costumbres y valores esenciales para su conservación como pueblos diferentes, pues de lo contrario se configuraría una forma de neocolonialismo, discriminación o segregación que el propio Estado lo rechaza según reza el numeral 6 del Art. 4 de la Constitución.

En el capítulo sobre derechos colectivos, la Constitución también nos da pautas de lo unitario y diverso, así, "Los pueblos indígenas, que se autodefinen como nacionalidades de raíces ancestrales, y los pueblos negros o afroecuatorianos, forman parte al Estado ecuatoriano, único e indivisible", lo que además anula las posiciones de algunos sectores que han limitado el tema a supuestos inexistentes como la división del país o la conformación de diversos estados $\mathrm{n}$ uno sólo. Otros preceptos del capítulo profundizan sobre los derechos colectivos que deben respetarse, y solamente mencionaremos algunos que tienen vinculación con las instituciones y autoridades de los pueblos indígenas, como mantener, desarrollar y fortalecer su identidad y tradiciones en lo espiritual, cultural, lingüístico, social, político y económico; conservar y desarrollar sus formas tradicionales de convivencia y organización social, de generación y ejercicio de la autoridad; lo cual no es sino reconocer que hay otras personas con sus propias formas de identidad, conciencia étnica y cultural.

\section{Materiales y métodos}

\section{Modelo de gestión}

- Recepción de materiales para la construcción de corrales al aire libre para las gallinas

- Construcción de corrales en las propiedades de los miembros de la asociación

- Recepción de curso de capacitación en crianza de gallinas criollas 
- Recepción de gallinas

- Cuidado y crianza de gallinas, alimentación, limpieza

- Cosecho de gallinas ya listas para vender utilizando protocoles de sanidad

- Distribución de pollos criollos en lugares de venta

- Pago de miembros de asociación e inversión de fondos para nuevas gallinas

Presupuesto inicial estimado por un periodo de un año

La Asociación Comunitaria Inka Huasi pide el apoyo financiero por medio de un préstamo de US\$10.000,00 para facilitar el establecimiento del Proyecto de gallinas criollas (costos detallados en tabla abajo). El préstamo sería devuelto dentro de un periodo por ser confirmado al interés de $5.0 \%$.

Tabla N 1 Presupuesto para el establecimiento del Proyecto de gallinas criollas

\begin{tabular}{|c|c|c|c|}
\hline Material & Precio por unidad & Numero unidades & Total \\
\hline \multicolumn{4}{|l|}{ Costos para establecer } \\
\hline Rollo malla metálica & $\$ 30,00$ & 10 & $\$ 300,00$ \\
\hline Tabla de madera & $\$ 4,00$ & 40 & $\$ 160,00$ \\
\hline Plancha sin (techo) & $\$ 8,00$ & 20 & $\$ 160,00$ \\
\hline Cartón de clavos, tornillos & $\$ 55,00$ & 1 & $\$ 55,00$ \\
\hline Polluelo gallina criolla & $\$ 15,00$ & 50 & $\$ 750,00$ \\
\hline \multicolumn{4}{|l|}{ Costos mantenimiento } \\
\hline $\begin{array}{l}\text { Alimentación gallina } \\
\text { (balanceado) }\end{array}$ & $\$ 20,00$ (quintal) & 72 & $\$ 1.440,00$ \\
\hline $\begin{array}{l}\text { Alimentación gallina (producto } \\
\text { fresco) }\end{array}$ & $\$ 35,00$ (mensual) & 12 & $\$ 460,00$ \\
\hline Mano de obra & $\begin{array}{l}\$ 15,00 \text { (diario } 2 \\
\text { personas) }\end{array}$ & 365 & $\$ 5.475,00$ \\
\hline Transporte personal y producto & $\$ 100$ (mensual) & 12 & $\$ 1.200,00$ \\
\hline TOTAL & & & $\$ 10.000,00$ \\
\hline
\end{tabular}

Fuente Elaboración propia

\section{Resultados}

El Ecuador tiene una gran riqueza cultural, llena de costumbres y tradiciones que se han mantenido en el trascurso del tiempo y que ahora nos permite conocer nuestro pasado para entender nuestro presente a su vez apreciarlo ya que solo se ama lo que se conoce. Y como por ejemplo de estas tablas de cómo organizar este proyecto nos damos cuenta de cómo manejar un negocio con las comunidades. 


\section{Análisis}

En ese trabajo podemos ver de cómo nos habla de sus tradiciones y saberes y de cómo podemos formar un proyecto con los pueblos o comunidades de ahí mismo sabemos todo y la mayoría somos descendientes de los indígenas que habitan en el Ecuador.

\section{Conclusiones}

- Un grupo étnico o una etnia es una colectividad que se identifica a sí misma y que es identificada por los demás conforme a criterios étnicos, y que comparte un sentimiento común de identidad con otros miembros del grupo.

- En sus tres regiones continentales conviven 14 nacionalidades indígenas con tradiciones diversas y su propia cosmovisión. Los nacionalidades indígenas amazónicas más conocidas son: Huaorani, Achuar, Shuar, Cofán, Siona-Secoya, Shiwiar y Záparo. Los tagaeri, parientes de los huaorani, conforman otro pueblo de la zona pero éste fue declarado como "intangible" por el Estado, en respeto a su voluntad de vivir alejados de la civilización.

- En la sierra, en los Andes y en el austro, están los quichuas de la sierra con pueblos como los otavalos, salasacas, cañaris y saraguros. En la parte norte se encuentra la comunidad de los AWA. En la costa del Pacífico están los Chachis, Cayapas, Tsáchilas y Huancavilcas. En las ciudades y pueblos viven principalmente mestizos, blancos y afroecuatorianos, aunque también se dan importantes migraciones del campo a la ciudad, lo cual ha generado problemas como el crecimiento de los suburbios y barrios marginales, falta de viviendas, escuelas y colegios, desempleo y delincuencia, entre otros.

\section{Referencias bibliográficas.}

huasalata, c. (2014). fomenta el pueblo indigena. pelileo.

raimundo, 1. r. (2013). grupos etnicos del ecuador. quito.

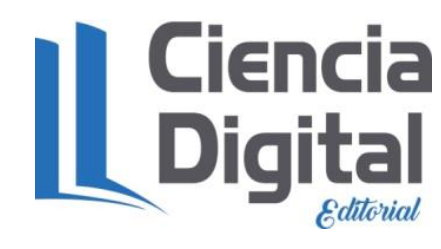


Para citar el artículo indexado.

Velasteguí López, P. (2018). Fortalecimiento de los pueblos indígenas del Ecuador. ConcienciaDigital, 1(1), 6-16. https://doi.org/10.33262/concienciadigital.v1i1.939

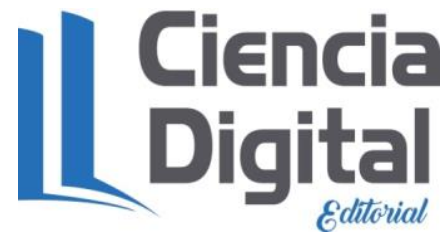

El artículo que se publica es de exclusiva responsabilidad de los autores y no necesariamente reflejan el pensamiento de la Revista Conciencia Digital.

El articulo queda en propiedad de la revista y, por tanto, su publicación parcial y/o total en otro medio tiene que ser autorizado por el director de la Revista Conciencia Digital.

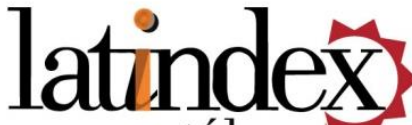

catálogo
Conciencia

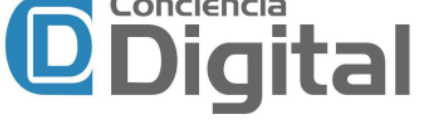

